\title{
Quinalizarin, a specific CK2 inhibitor, can reduce icotinib resistance in human lung adenocarcinoma cell lines
}

\author{
$\mathrm{KE} \mathrm{LI}^{1^{*}}$, FANGZHENG ZHOU $^{2 *}, \mathrm{YU} \mathrm{ZHOU}^{3}$, SHENG ZHANG ${ }^{2}$, QIANWEN LI $^{2}$, \\ ZHENYU LI ${ }^{2}$, LI LIU ${ }^{2}$, GANG WU ${ }^{2}$ and RUI MENG ${ }^{2}$ \\ ${ }^{1}$ Pharmacy Department and ${ }^{2}$ Cancer Center, Union Hospital, Tongji Medical College, Huazhong University \\ of Science and Technology, Wuhan, Hubei 430022; ${ }^{3}$ Department of Nuclear Medicine, Tongji Hospital, \\ Tongji Medical College, Huazhong University of Science and Technology, Wuhan, Hubei 430030, P.R. China
}

Received February 16, 2018; Accepted May 15, 2019

DOI: $10.3892 /$ ijmm.2019.4220

\begin{abstract}
The abnormal activation of the downstream signaling pathways of epidermal growth factor receptor (EGFR) that are independent of EGFR, contribute to the acquisition of EGFR-tyrosine kinase inhibitor (TKI) resistance in non-small cell lung cancer (NSCLC). The serine/threonine protein kinase casein kinase II (CK2) phosphorylates and modulates several members of the EGFR downstream signaling pathways. Thus, the purpose of the current study was to investigate the effects of the addition of quinalizarin (a specific CK2 inhibitor) to icotinib (an EGFR-TKI) on the proliferation and apoptosis of four NSCLC cell lines and its underlying mechanisms. The human lung adenocarcinoma cell lines HCC827, A549, H1650 and H1975 were employed to represent the EGFR-TKI-sensitive EGFR (EGFR-sensitive) mutation, wild-type EGFR and the EGFR-TKI-resistant EGFR (EGFR-resistant) mutations. The cell viability was determined by the MTT assay. Cell apoptosis was detected by flow cytometry using the Annexin V-enhanced green fluorescent protein Apoptosis Detection kit. The level of proteins in the EGFR downstream pathway was observed using a western blot assay. The results showed that the cells with the EGFR-sensitive mutation (HCC827, EGFR E716-A750del) were more sensitive to icotinib compared with those possessing the EGFR wild-type (A549) and the EGFR-resistant mutations (H1650, EGFR E716-A750del and PTEN lost; H1975, EGFR L858R+T790M). Quinalizarin inhibited proliferation and promoted apoptosis in the cells with the EGFR wild-type and resistant mutations, and
\end{abstract}

Correspondence to: Professor Rui Meng, Cancer Center, Union Hospital, Tongji Medical College, Huazhong University of Science and Technology, 156 Wujiadun Road, Wuhan, Hubei 430022, P.R. China

E-mail: mengruivip@163.com

${ }^{*}$ Contributed equally

Key words: protein kinase casein kinase II, quinalizarin, icotinib, proliferation, apoptosis the addition of quinalizarin to icotinib partially restored their sensitivity to icotinib. Quinalizarin and/or icotinib increased the apoptotic rates in the EGFR-TKI resistant cells, and the combination of these reduced the level of protein downstream of EGFR, including phosphorylated (p-AKT) and p-(ERK). In conclusion, quinalizarin may partially sensitize cells to icotinib by inhibiting proliferation and promoting apoptosis mediated by AKT and ERK in EGFR-TKI resistant NSCLC cell lines.

\section{Introduction}

Non-small cell lung cancer (NSCLC) accounts for approximately $85 \%$ of lung cancer cases and $10-30 \%$ of patients with NSCLC bear activating mutations in the epidermal growth factor receptor gene $(E G F R)(1)$. A prospective, multinational PIONEER study confirmed that there is an even higher EGFR mutation frequency (51.4\% overall) in tumors from Asian patients with lung adenocarcinoma compared with their Caucasian counterparts (2). Almost $75 \%$ of patients with activated EGFR mutations have a longer median overall survival and better response rates when they are treated with an EGFR-tyrosine kinase inhibitor (EGFR-TKI) compared with only traditional platinum-based chemotherapy (3-6). Regretfully, most invariably develop or 'acquire' resistance to these agents during the treatment course (7).

Icotinib (also known as BPI-2009H and Conmana) is the first oral quinazoline compound that has an established survival benefit and fewer side effects in Chinese patients with NSCLC $(8,9)$. A network meta-analysis demonstrated that icotinib shares equivalent efficacies with erlotinib, gefitinib and afatinib, but has a lower toxicity (10). The double-blind, head-to-head phase III ICOGEN study indicated that icotinib demonstrated an improved median progression-free survival compared with gefitinib and was also associated with fewer adverse events compared gefitinib when considering all grades of reactions together (11).

By acting on signaling pathways, including PI3K-AKTmTOR, Ras-Raf-MEK-ERK and STAT, an EGFR-TKI regulates cell proliferation, apoptosis, invasion, migration and angiogenesis (12). A growing body of evidence has elucidated the mechanism of EGFR-TKI resistance (13). Although 
almost half of all TKI resistance is caused by a secondary T790M mutation (14), the abnormal activation, independent of EGFR, of EGFR's downstream signaling pathways, such as PI3K-AKT-mTOR (15), also contributes to the acquisition of resistance.

The protein kinase casein kinase II (CK2) is an evolutionary, highly conserved serine/threonine kinase that phosphorylates and interacts with more than 300 proteins (16). It is noteworthy that several members of the EGFR downstream singling pathways (Fig. 1), including PTEN, ribosomal protein S6 kinase $\beta-1$ (S6) and AKT within the PI3K-AKT-mTOR signaling pathway, have been previously reported to be phosphorylated or modulated by CK2 $(17,18)$. Quinalizarin is known as a potent, selective and cell-permeable inhibitor of CK2 (19). A previous study revealed that quinalizarin reduced cell viability, suppressed migration and accelerated apoptosis in different human lung cancer cell lines with wild-type $E G F R$ and EGFR-resistant mutations, as well as for those with an EGFR-sensitive mutation (20). Therefore, the authors of the current study hypothesized that a top-down inhibition of EGFR, combined with the lateral suppression of its multiple downstream pathways by targeting CK2 would create a pharmacologic synthetic lethal event and result in the resistance to EGFR-TKIs being overcome. The purpose of the current study was to investigate the effects of icotinib and quinalizarin on proliferation and apoptosis in four human lung adenocarcinoma cell lines (A549, HCC827, H1650 and H1975) with different $E G F R$ genotypes, as well as to reveal quinalizarin's underlying mechanisms.

\section{Materials and methods}

Cell lines. Human lung adenocarcinoma A549 (wild-type $E G F R$ ), HCC827 (EGFR E716-A750del), NCI-H1975 (EGFR L858R+T790M), NCI-H1650 (EGFR E716-A750del and PTEN lost) cells were purchased from the American Type Culture Collection (Manassas, VA, USA) and were used within 3 months of resuscitation. The cells were cultured in RPMI 1640 supplemented with 10\% fetal calf serum (FCS) and $1 \%$ penicillin/streptomycin (all Gibco; Thermo Fisher Scientific, Inc., Waltham, MA, USA), which will be termed culture medium henceforth, in a humidified atmosphere of $5 \% \mathrm{CO}_{2}$ and $95 \%$ air at $37^{\circ} \mathrm{C}$.

Reagents. Icotinib was from Betta Pharmaceuticals Co., Ltd. (Hangzhou, China). The specific CK2 inhibitor quinalizarin was purchased from Merck KGaA (Darmstadt, Germany).

Cell viability assays. For each cell line, the cells were harvested at the logarithmic phase and were then seeded into a 96-well plate at a density of 6,000 cells per well with $100 \mu \mathrm{l}$ culture medium. The cells were cultured at $37^{\circ} \mathrm{C}$ with $5 \% \mathrm{CO}_{2}$ overnight, and then various concentrations of icotinib and/or quinalizarin were added to each well $(6.25,12.5,25$, 50 and $100 \mu \mathrm{M}$ ), with a total of $200 \mu \mathrm{l}$ culture medium and were further incubated for $48 \mathrm{~h}$. Thereafter, $20 \mu \mathrm{l}$ of the MTT solution (Wuhan Boster Biological Technology, Ltd., Wuhan, China) was added into each well. A total of $4 \mathrm{~h}$ later, $150 \mu \mathrm{l}$ dimethyl sulfoxide (DMSO) was used to dissolve the crystals. The plates were placed on a low-speed shaker for $10 \mathrm{~min}$ to fully dissolve the crystals. The optical density (OD) of each well was read at a wavelength of $490 \mathrm{~nm}$ using a microplate reader. A cell viability curve was plotted using the concentration as the $\mathrm{x}$-axis and the cell viability rate as the $y$-axis. The blank control group was incubated in culture medium without treatment. The values were calculated as follows: Cell survival rate $=(O D$ value of experimental well-OD value of blank control well)/(OD value of no drug control well-OD value of blank control well) $\times 100 \%$.

Each experiment was independently repeated at least three times for each cell line. The dose-effect relationship was fitted using curve regression models to obtain the $50 \%$ inhibitory concentration of $6.25,12.5,25,50$ and $100 \mu \mathrm{M}$ icotinib, quinalizarin, and icotinib and quinalizarin combined by GraphPad Prism software (version 5.0; GraphPad Software, Inc., San Diego, CA, USA).

Apoptosis assays. Annexin V-enhanced green fluorescent protein (EGFP)-propidium iodide (PI) staining and flow cytometry were performed to detect cell apoptosis. Cells $\left(1 \times 10^{4} / \mathrm{cm}^{2}\right)$ in the logarithmic growth phase were plated into 12-well plates with fresh culture medium. After $24 \mathrm{~h}$, for attachment, the cells were washed with PBS two to three times, and then $6.25,12.5,25,50$ and $100 \mu \mathrm{M}$ icotinib and/or quinalizarin were added to EGFR-resistant cell lines. The cells were cultured with a trypsin enzyme digesting technique $48 \mathrm{~h}$ later and cell apoptosis was assessed using an Annexin V-EGFP Apoptosis Detection kit (cat. no. C1067M; Beyotime Institute of Biotechnology, Shanghai, China) following the product specifications.

Cell morphology. H1650, H1975 or A549 cells $\left(1 \times 10^{4} / \mathrm{cm}^{2}\right)$ were seeded into a 6-well plate for $24 \mathrm{~h}$, washed with PBS two to three times, and then $6.25,12.5,25,50$ and $100 \mu \mathrm{M}$ icotinib and/or quinalizarin were added. After $48 \mathrm{~h}$, the cells were fixed with $4 \%$ paraformaldehyde at room temperature for $20 \mathrm{~min}$, morphology was observed by a light microscope (IX71; Olympus Optical, Tokyo, Japan) at a magnification of x100 and images were taken.

Western blot analysis. The cells $\left(1 \times 10^{4} / \mathrm{cm}^{2}\right)$ were seeded into a 6-well plate for $24 \mathrm{~h}$. Then, different concentrations of drugs (50 $\mu \mathrm{M}$ icotinib or/and quinalizarin) were applied to the cells and they were further incubated $24 \mathrm{~h}$. Thereafter, the cells were lysed in radioimmunoprecipitation assay buffer, phenylmethylsulfonyl fluoride and a phosphatase inhibitor cocktail, which were purchased from Wuhan Google Biological Technology Co., Ltd. (Wuhan, China). The protein concentration was measured on a microplate reader according to the bicinchoninic acid method. Protein $(50 \mu \mathrm{g} / \mathrm{lane})$ from the cell lysates were electrophoresed by SDS-PAGE on a $12 \%$ gel and were transferred to a polyvinylidene difluoride membrane. The membrane was blocked with 5\% dry milk at room temperature for $1 \mathrm{~h}$ and was then incubated with anti-p-ERK (cat. no. 4370S), anti-EGFR (cat.no. ab289; Abcam, Cambridge, MA, USA), anti-CK2 $\alpha$ (\#212), anti-CK2 $\beta$ (\#269), anti-AKT (cat. no. 1081-1; Epitomics; Abcam), anti-p-AKT (pS473; cat. no. 2118-1; Epitomics; Abcam) anti-ERK (cat. no. BS1112; Bioworld Technology, Inc., St. Louis Park, MN, USA), anti-p-EGFR (cat. no. AF3048, Affinity), anti-p-forkhead box 


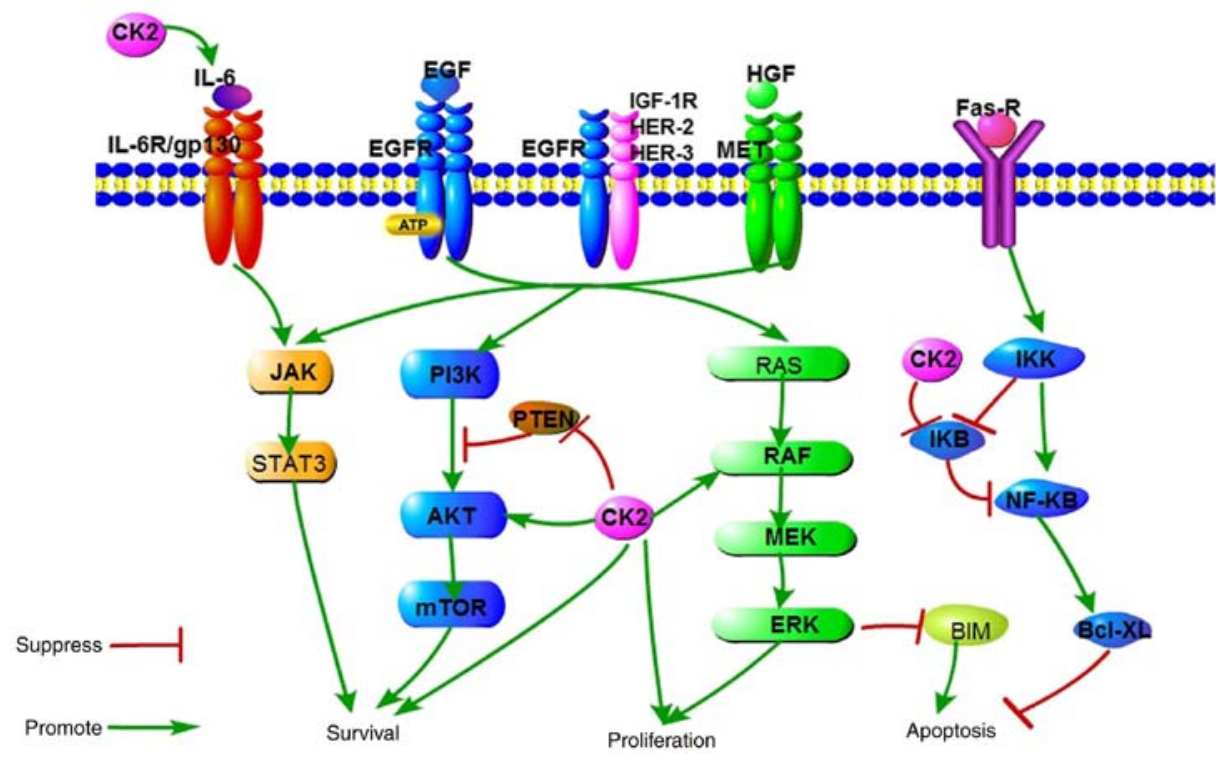

Figure 1. A schematic representation of signaling pathways responsible for cell survival, proliferation and apoptosis, which are regulated by EGFR and CK2. CK2, casein kinase II; EGF, epidermal growth factor; EGFR, epidermal growth factor receptor; MEK, dual specificity mitogen-activated protein kinase kinase; IкB, NF-к-B inhibitor; IKK, IкB kinase; BIM, Bcl-2-like protein 11; IL-6R, interleukin-6 receptor; IGF-1R, insulin-like growth factor 1 receptor; HER, receptor tyrosine-protein kinase erbB-4; HGF, hepatocyte growth factor; MET, hepatocyte growth factor receptor.

protein O1 (FoxO1; cat. no. 9461), anti-p-S6 (cat. no. 2211; both Cell Signaling Technology, Inc.) or anti- $\beta$-actin (cat. no. sc-1616r; Santa Cruz Biotechnology, Inc., Dallas, TX, USA) antibodies diluted at 1:1,000 in $5 \%$ bovine serum albumin (BSA; cat. no. AR1006; Wuhan Boster Biological Technology, Ltd.) at $4^{\circ} \mathrm{C}$ overnight. After washing with $1 \mathrm{X}$ PBS, the membrane was incubated with horseradish peroxidase-conjugated anti-mouse (cat. no. 5450-0011) or anti-rabbit (cat. no. 5220-0336) secondary antibodies (Kirkegaard \& Perry Laboratories; SeraCare Life Sciences, Inc., Milford, MA, USA) diluted at 1:500 in 5\% BSA at room temperature for $1 \mathrm{~h}$. The proteins were observed with Western Blotting Luminol Reagent (sc-2048; Santa Cruz Biotechnology, Inc.). The intensity of the bands underwent densitometric analysis and they were calculated using AlphaEase FC software (version 5.0; Alpha Innotech Corporation, San Leandro, CA, USA). Anti-CK2 $\alpha$ (\#212) and anti-CK2 $\beta$ (\#269) antibodies were generated as described previously (21) and were kind gifts from Professor Mathias Montenarh from Medical Biochemistry and Molecular Biology, Saarland University (Homburg, Germany).

Statistical analysis. Data are presented as mean \pm standard deviation. All the statistical analyses were performed with two-way analysis of variance followed by Bonferroni test using GraphPad Prism software (version 5.0). Statistical diagrams were generated using GraphPad Prism software (version 5.0). $\mathrm{P}<0.05$ indicated that the difference between groups was statistically significant.

\section{Results}

Cell lines with different EGFR genotypes have different basal expressions of CK2 and EGFR. To explore whether targeting CK2 eliminates icotinib-resistance, the basal protein expression of the catalytic CK2 subunit and EGFR were assessed in the four aforementioned lung adenocarcinoma cell lines with different $E G F R$ genotypes, namely, A549 (wild-type EGFR), HCC827 (EGFR E716-A750del), NCI-H1975 (EGFR L858R+T790M) and NCI-H1650 (EGFR E716-A750del and PTEN lost). HCC827 has been demonstrated to be sensitive to EGFR-TKIs, while A549, NCI-H1975 and NCI-H1650 are known as EGFR-TKI resistant cell lines $(22,23)$.

As presented in Fig. 2, the protein expression of the CK2 catalytic subunit $\alpha$ was strong and was clearly overexpressed in the HCC 827 and NCI-H1650 cells compared with the A549 cells. It was notable that in the NCI-H1975 cells, there was markedly less CK2 $\alpha$ protein expression compared with the other cells. Total EGFR and p-EGFR expression levels were also detected. The results revealed that EGFR expression within those four cell lines differed greatly, with the HCC 827 cells containing the highest amount of total EGFR and the second highest amount of the phosphorylated form of EGFR. On the other hand, the lowest amount of total EGFR expression and the highest amount of the phosphorylated form were observed in NCI-H1650 cells. In addition, total EGFR expression in A549 and NCI-H1975 cells was relatively the same, which were markedly lower compared with in the HCC 827 cells and markedly higher compared with the NCI-H1650 cells. The amount of phosphorylated form of EGFR in A549 and NCI-H1975 cells was clearly lower when compared with the HCC827 and NCI-H1650 cells, with the least amount in the NCI-H1975 cells.

Sensitivity to icotinib is different in various lung adenocarcinoma cell lines and is closely associated with the EGFR genotype. To test the sensitivity of icotinib in different human lung adenocarcinoma cell lines with various $E G F R$ genotypes, the cells were exposed to various concentrations of icotinib for $48 \mathrm{~h}$. Then, the MTT assay was used to determine the cell viability. Fig. 3 demonstrates that the HCC 827 cells were sensitive to icotinib, while the other three cell lines were 

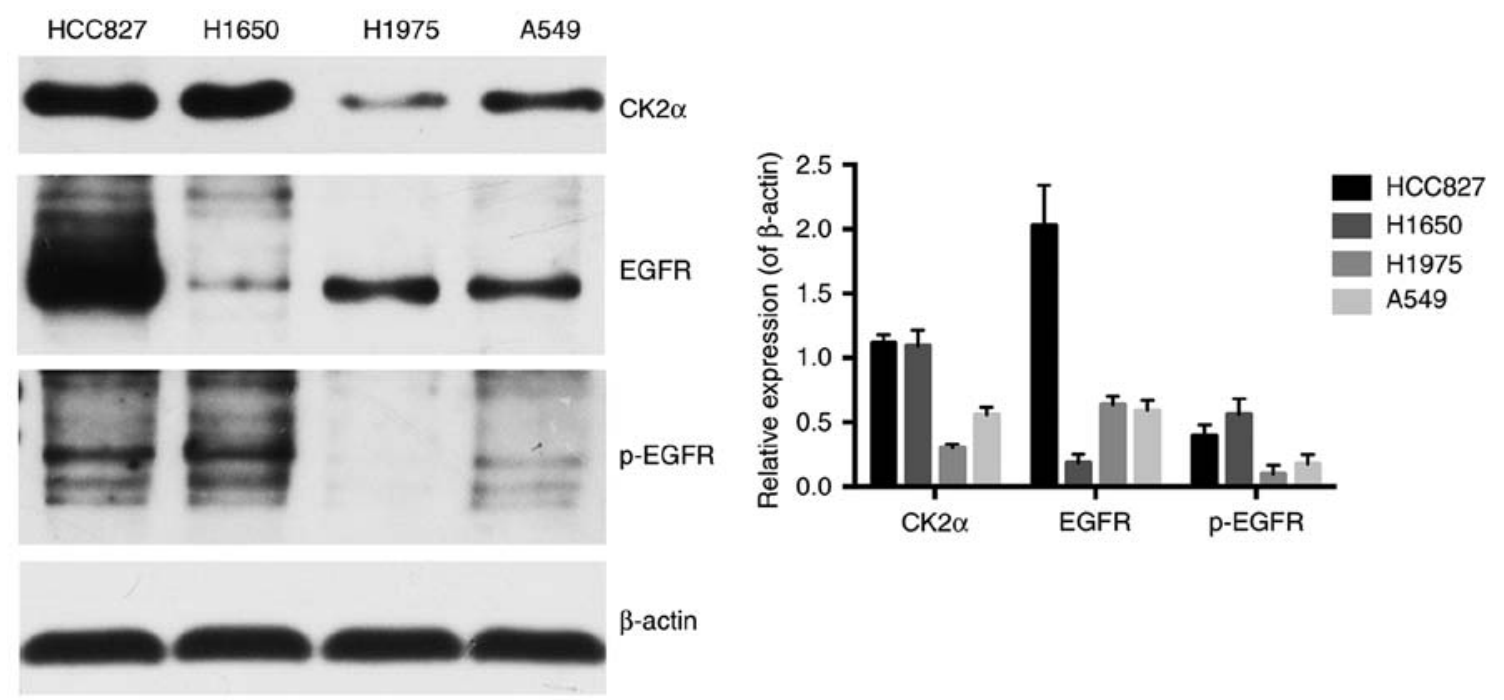

Figure 2. Cell lines with different EGFR genotypes have different basal expressions of CK2 and EGFR. Western blotting images, and quantification of CK2 $\alpha$, EGFR and p-EGFR protein expression. $\beta$-actin was used as a loading control. The mean \pm standard deviation was calculated for three independent experiments. CK $2 \alpha$, casein kinase II subunit $\alpha$; EGFR, epidermal growth factor receptor; p-, phosphorylated.

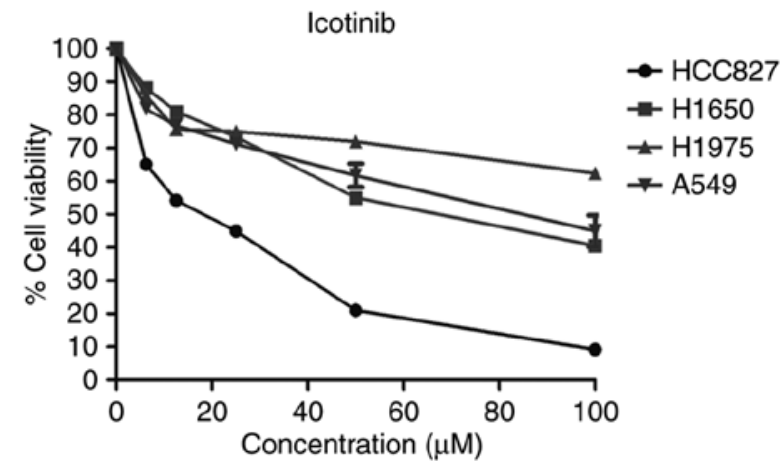

Figure 3. Sensitivity to icotinib is different in various lung adenocarcinoma cell lines and is closely associated with the EGFR genotype. The cells were treated with different concentrations of icotinib. Cell viability was assessed using an MTT assay after $48 \mathrm{~h}$. Data are expressed as a percentage in relation to dimethyl sulfoxide. The mean \pm standard deviation was calculated from three independent experiments. EGFR, epidermal growth factor receptor.

resistant to icotinib. The sensitivity of the cells to icotinib depended on their EGFR genotypes, as described previously. Moreover, the levels of EGFR and p-EGFR were also closely related with the different EGFR genotypes. The H1975 cells, which are EGFR-mutant on both L858R and T790M, showed the lowest level of p-EGFR (Fig. 2) and the least sensitivity to the icotinib (Fig. 3).

Quinalizarin inhibits the cell viability of all four cell lines and promotes apoptosis in cell lines with wild-type EGFR and EGFR-resistant mutations. The MTT assay was also used to explore the influence of quinalizarin on these four cell lines; the results showed that quinalizarin suppressed cell viability. Additionally, CK2 $\alpha$ expression was negatively associated with cell viability (Figs. 2 and 4A). The highest inhibition rate was found in the HCC827 cells, which are known to bear an EGFR-sensitive mutation. Thereafter, the total apoptosis rates of the resistant cell lines were tested by flow cytometry after treatment with quinalizarin for $48 \mathrm{~h}$ (Fig. 4B). The result showed that quinalizarin promoted apoptosis in H1650, H1975 and A549 cells, with the strongest effect being shown in the A549 cells bearing the EGFR wild-type genotype (Fig. 4C).

Quinalizarin enhances the suppression of cell viability mediated by icotinib in both primary and secondary drug resistant cell lines. From the above experiments, the authors of the current study found that quinalizarin and icotinib, individually, suppressed the viability of four different lung adenocarcinoma cells. The cell viability after the cells were treated with a combination of quinalizarin and icotinib was then evaluated (Fig. 5). Fig. 5A shows that quinalizarin did not enhance the reduction of cell viability mediated by icotinib in the HCC 827 cells. However, quinalizarin enhanced the suppression of cell viability mediated by icotinib in A549, H1650 and H1975 cell lines, which were shown to be primary or secondary EGFR-TKI resistant cell lines. When treated with $100 \mu \mathrm{M}$ quinalizarin and icotinib, the viability of A549 cells were significantly lower than that of cells treated with quinalizarin $(\mathrm{P}<0.05)$ or icotinib $(\mathrm{P}<0.01)$ alone (Fig. $5 \mathrm{~B})$. When treated with $100 \mu \mathrm{M}$ quinalizarin and icotinib, the viability of H1650 and H1975 cells were significantly lower than that of cells treated with quinalizarin or icotinib alone (all $\mathrm{P}<0.001$; Fig. 5C and D). Moreover, the suppression effect was more prominent in the H1650 cells.

Quinalizarin increases the apoptosis rate of EGFR-resistant cells when treated together with icotinib. As described previously, quinalizarin enhanced the suppression of cell proliferation mediated by icotinib in both primary and secondary drug resistant cell lines. To determine how these effects occur, flow cytometry was performed to assess the apoptosis rates after the cells were treated with quinalizarin and icotinib. Fig. 6A shows that the combination of $100 \mu \mathrm{M}$ quinalizarin and icotinib significantly increased the total apoptosis rate of the H1650 cells compared with quinalizarin or icotinib alone (both $\mathrm{P}<0.001$ ). In addition, Fig. 6B shows that H1650 cell morphology changed after the cells were 
A
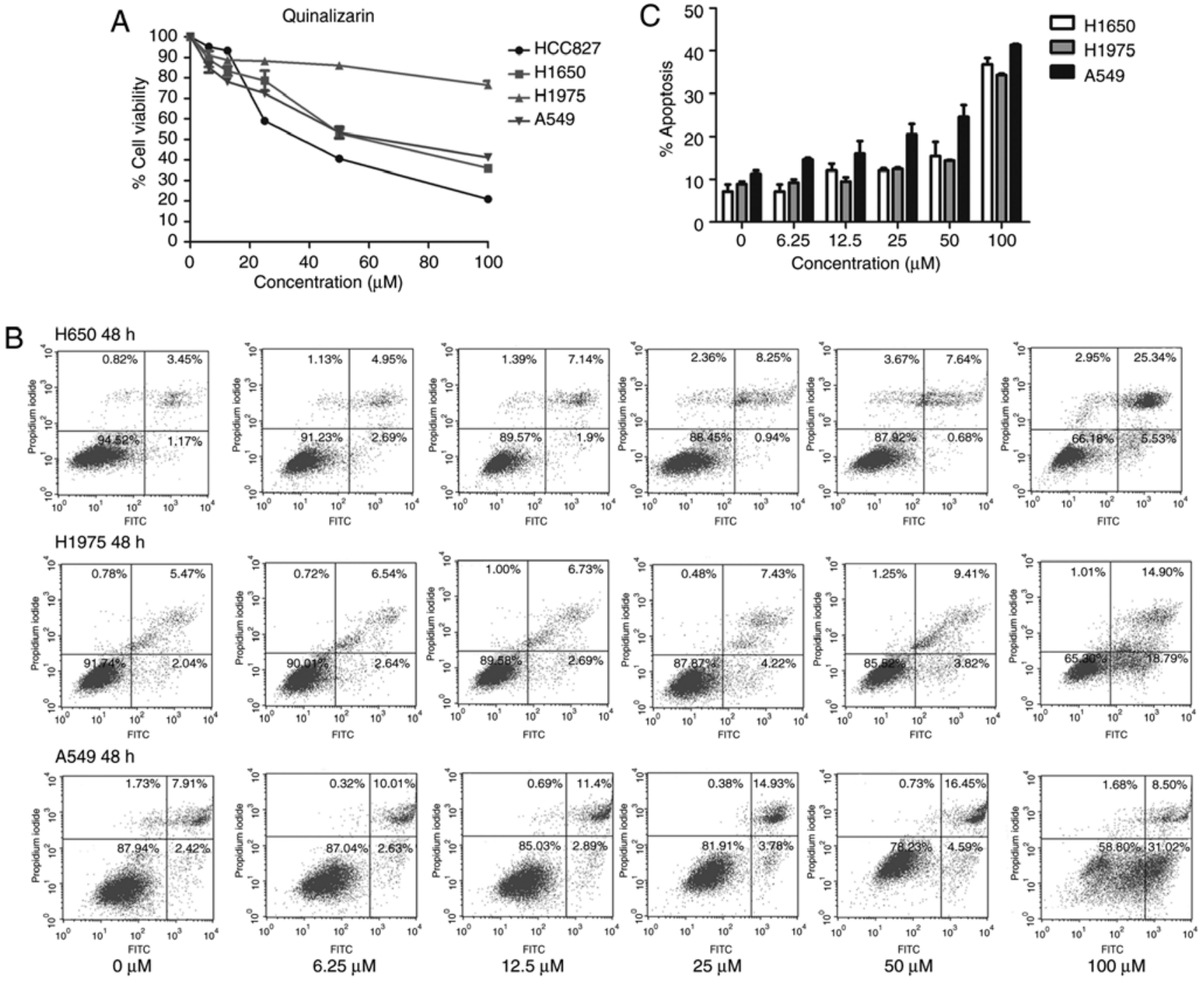

Concentration

Figure 4. Quinalizarin inhibits the cell viability of all four cell lines and promotes apoptosis in cell lines with wild-type EGFR and EGFR-resistant mutations. The cells were treated with different concentrations of quinalizarin. (A) Cell viability was assessed using an MTT assay after $48 \mathrm{~h}$. Data are expressed as a percentage in relation to dimethyl sulfoxide. (B) Cell apoptosis was measured by a flow cytometry. The lower left square represents living cells, the lower right square represents early apoptotic cells, the upper right square represents late apoptotic cells and the upper left square represents necrotic cells. The control group was treated with the equal concentration of dimethyl sulfoxide. (C) Quantification of total apoptosis rates. The mean \pm standard deviation was calculated from three independent experiments. EGFR, epidermal growth factor receptor.

treated with both quinalizarin and icotinib. The cells treated with the combination of the drugs were small and round, and some of them showed obvious vacuolization. These changes are considered signs of cell apoptosis. Thus, the authors of the current study deduced that quinalizarin, together with icotinib, mediated cell apoptosis and increased the apoptosis rate in the H1650 cells. Similar results were also observed in H1975 (Fig. 6C and D) and A549 (Fig. 6E and F).

The total apoptosis rate and cell morphology in H1650, H1975 and A549 were shown in Fig. 6. Data showed that the combination treatment enhanced the total apoptosis rate compared with quinalizarin or icotinib alone in all cell lines $(\mathrm{P}<0.0001$ at $100 \mu \mathrm{M})$. The results also suggested that the largest increase in the total apoptosis rate was in the H1650 cells after they were treated with both drugs. protein expression in EGFR-resistant cell lines. It was shown earlier that quinalizarin may sensitize lung adenocarcinoma cancer cells to icotinib by inhibiting cell viability and promoting apoptosis. To further explore the underlying mechanisms, a western blot analysis was performed to assess whether the combination of these two drugs resulted in a reduction of the EGFR signaling pathways. A previous study showed that the efficacy of EGFR-TKIs was partly due to the modulation of the PI3K-AKT-mTOR and the Ras-Raf-MEK-ERK signaling pathways (12). Several specific CK2 inhibitors have also already been shown to work with these two pathways $(24,25)$. Since AKT and ERK are regarded as key members of these pathways, the authors of the current study mainly evaluated the levels of EGFR, CK $2 \alpha, \mathrm{CK} 2 \beta$, AKT and ERK, and the corresponding phosphorylated forms of EGFR, AKT, ERK, FoxO1 and S6 (Fig. 7); FoxO1 and S6 are downstream of AKT (26).

The results showed that p-EGFR was significantly downregulated by combining $50 \mu \mathrm{M}$ quinalizarin and $50 \mu \mathrm{M}$ icotinib 
A

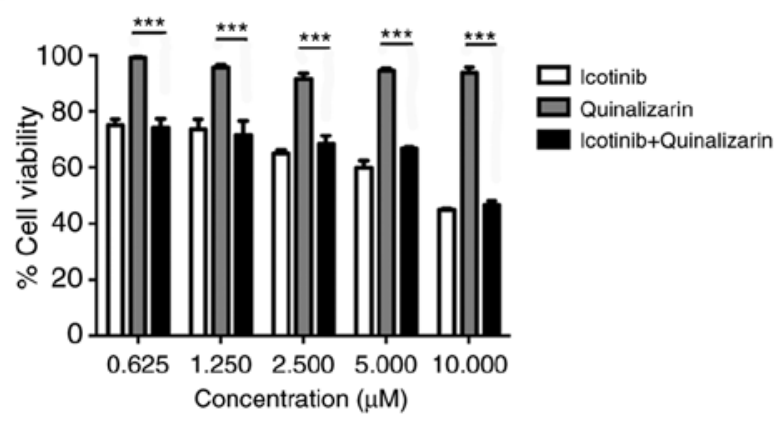

C

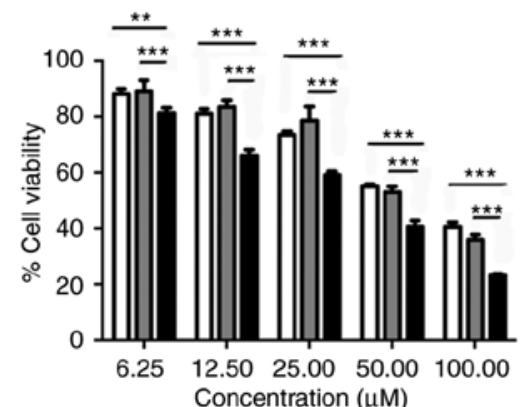

$\mathrm{B}$

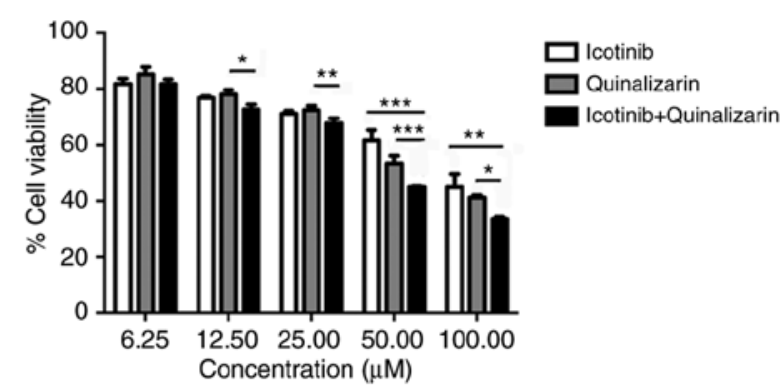

D

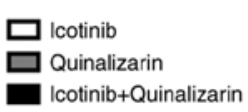

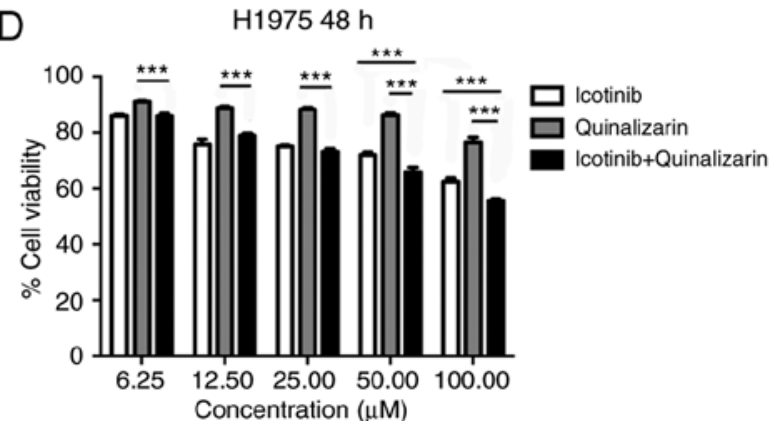

Figure 5. Quinalizarin enhances the suppression of cell viability mediated by icotinib in both primary and secondary drug resistant cell lines. The cells were treated with different concentrations of quinalizarin. The control group was treated with the equal concentration of dimethyl sulfoxide. The viability of (A) HCC827, (B) A549, (C) H1650 and (D) H1975 cells was assessed using an MTT assay after $48 \mathrm{~h}$. The mean \pm standard deviation was calculated from three independent experiments. ( $\left.\mathrm{P}<0.05,{ }^{* *} \mathrm{P}<0.01,{ }^{* * *} \mathrm{P}<0.001\right)$.

compared with quinalizarin alone $(\mathrm{P}<0.05$ in $\mathrm{H} 1650$ and $\mathrm{P}<0.01$ in $\mathrm{H} 1975$ ) and icotinib alone (both $\mathrm{P}<0.001)$. The combination treatment also significantly decreased the expression of p-AKT in both cells lines (all $\mathrm{P}<0.001$ ), p-ERK in $\mathrm{H} 1650$ cells (both $\mathrm{P}<0.001)$ and in $\mathrm{H} 1975$ cells $(\mathrm{P}<0.01$ for icotinib alone and $\mathrm{P}<0.001$ for quinalizarin alone), $\mathrm{p}-\mathrm{FoxO} 1$ in $\mathrm{H} 1650$ cells (both $\mathrm{P}<0.001$ ) and in $\mathrm{H} 1975$ cells (both $\mathrm{P}<0.05$ ), and $\mathrm{p}-\mathrm{S} 6$ in $\mathrm{H} 1650$ $(\mathrm{P}<0.01$ for icotinib alone) and in $\mathrm{H} 1975$ cells $(\mathrm{P}<0.05$ for quinalizarin alone and $\mathrm{P}<0.001$ for icotinib alone).

\section{Discussion}

EGFR-TKIs provide a way to improve the treatment outcomes for lethal NSCLC (4-6). However, the critical problems related to EGFR-TKIs is unavoidable drug resistance, which prevents patients from further benefits (22). The authors of the current study illustrated several ways in which EGFR-TKIs work and discussed the possible mechanisms devoted to the drug resistance.

In accordance with a great body of literature, the current study found that the protein kinase CK2 was almost connected, either indirect or directly, to all analysed pathways, including PTEN, S6 and AKT within the PI3K-AKT-mTOR signaling pathway $(17,18)$ as well as RAF within the Ras-Raf MEK-ERK downstream pathway (27). CK2 has recently emerged as a promising target for lung cancer therapy (28). It is a ubiquitous serine/threonine protein kinase that has been demonstrated to be involved in cell growth and proliferation, as well as in inhibiting apoptosis $(16,25)$. Other studies have revealed that the activity of CK2 is up to 2-3-fold higher in lung cancer cells compared with normal lung tissues $(20,29)$. Hung et al (30) revealed that the CK2 inhibitor suppressed lung cancer growth in a murine xenograft model. Li et al (31) found that the CK2 inhibitor quinalizarin reduced cell proliferation and induced apoptosis in NSCLC cells. Kim and Kim (32) reported that the CK2 inhibitor CX-4945 suppressed the proliferative activity of human cancer cells. Ku et al (33) showed that CX-4945 induced cell migration and suppressed metastasis in A549 human lung cancer cells. Di Maira et al (34) demonstrated that the inhibition of CK2 reversed the multidrug resistance in a CEM cell line with a high CK2 level. Thus, the authors of the current study deduced that CK2 inhibitors might not only have antineoplastic effects but also partly reverse the EGFR-TKI-resistance of human lung adenocarcinoma cell lines.

The current study showed that the sensitivity of lung adenocarcinoma cells to icotinib was different between the cell lines and was associated with various $E G F R$ mutation types. The cells with an EGFR-sensitive mutation (HCC827) were more sensitive to icotinib than those that possessed wild-type EGFR (A549) and those with an EGFR-resistant mutation (H1650 and H1975). The reason that icotinib prevented the tumor from growing is because it competed for EGFR binding and inhibited the downstream signaling pathways, such as PI3K-AKT-mTOR, Ras-Raf-Mek-ERK and STAT. The current study demonstrated that the downstream signaling pathways were normally overexpressed or activated in the EGFR-sensitive mutant cell line (HCC827) and these pathways play a prominent role in cell growth (35). The inhibition of these pathways showed a more remarkable anti-tumor effect and HCC 827 cells were more sensitive to icotinib. The A549, which possesses wild-type $E G F R$, has fewer activated basal pathways and is less sensitive to EGFR-TKIs $(36,37)$. 
A
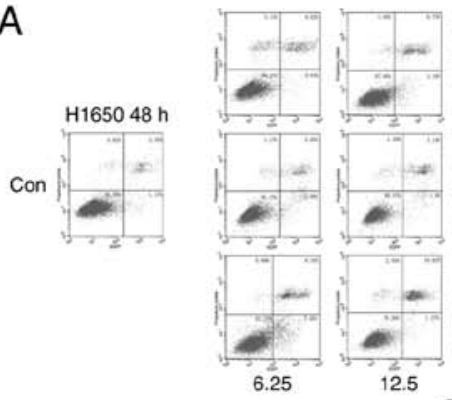

B

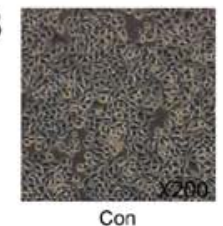

Con

C
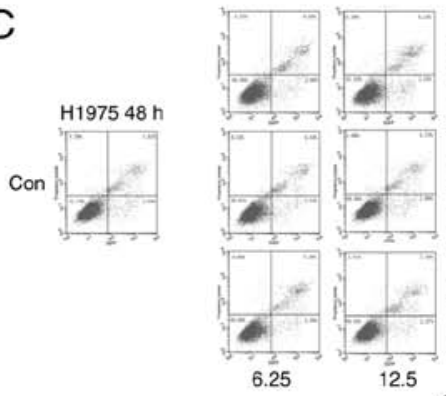

D

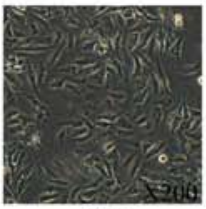

Con
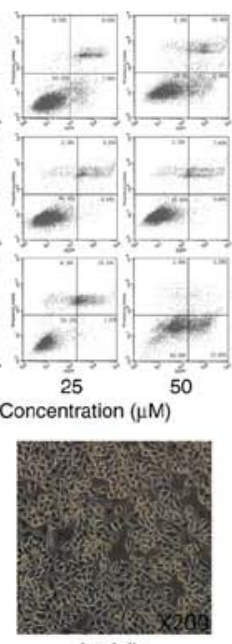

Icotinib
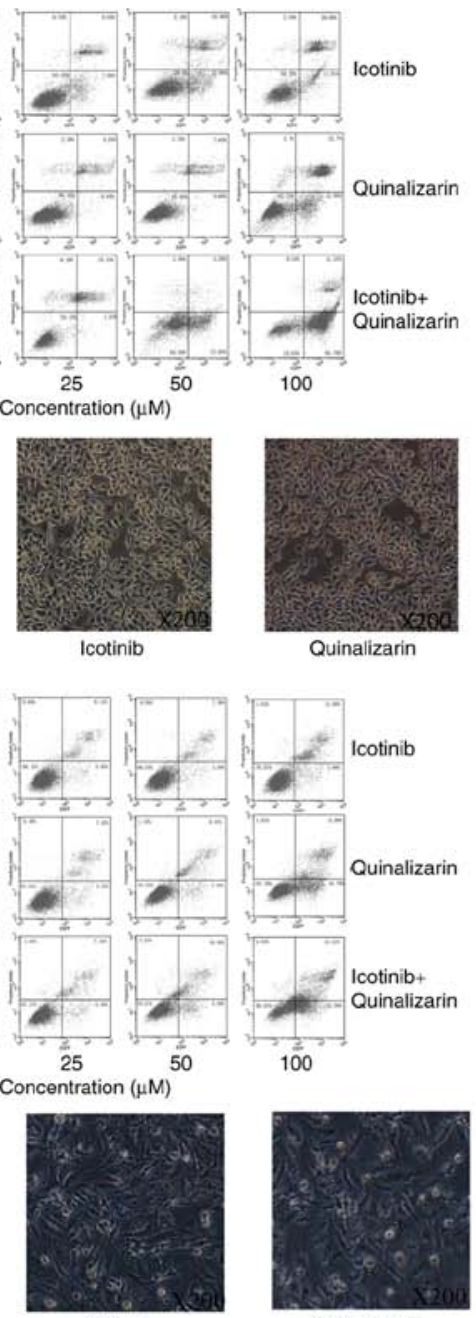

Quinalizarin
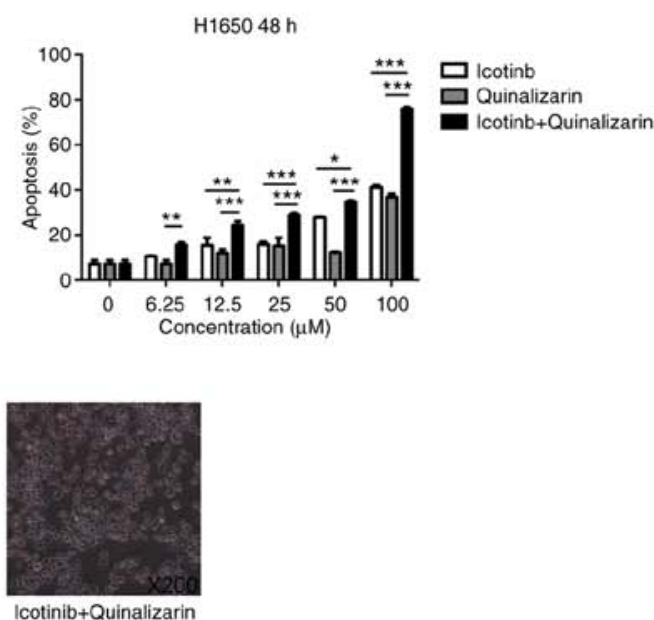

Icotinib+Quinalizarin
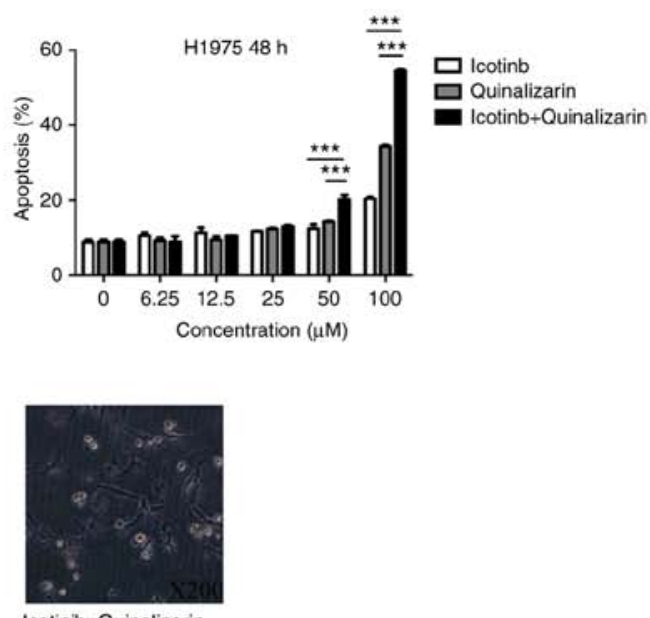

Icotinib+Quinalizarin

$\mathrm{E}$
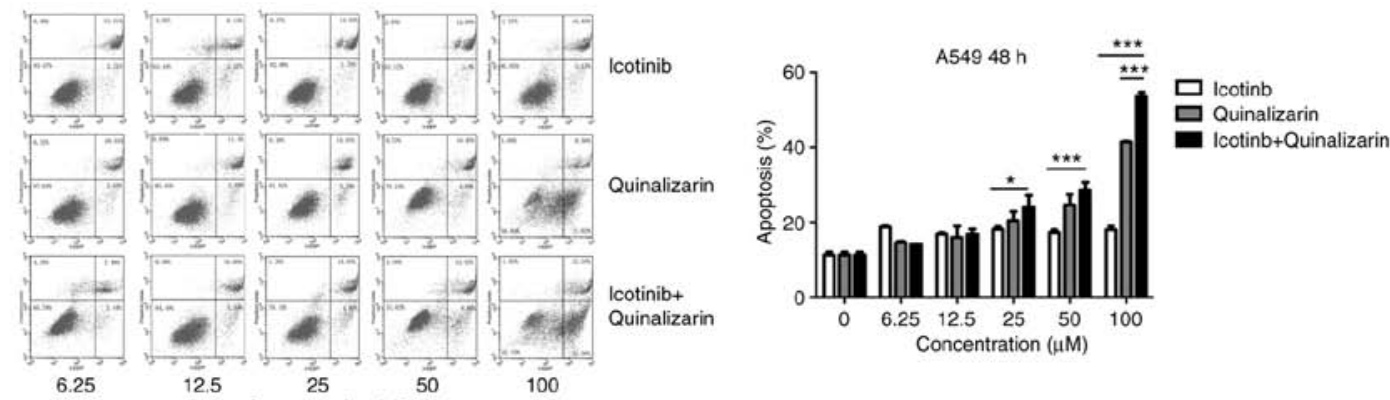

$\mathrm{F}$
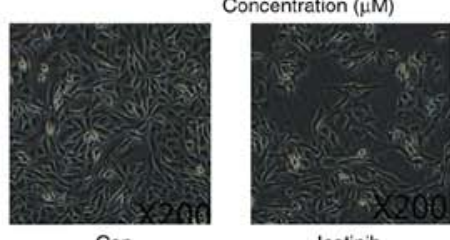

Icotinib

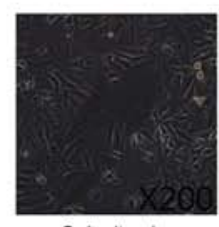

Quinalizarin

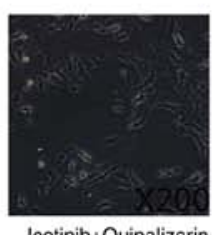

Icotinib+Quinalizarin

Figure 6. Quinalizarin increases the apoptosis rate of EGFR-resistant cells when treated together with icotinib. Wild-type EGFR and EGFR-resistant cells were treated with different concentration of icotinib and/or quinalizairn. The control group was treated with the equal concentration of dimethyl sulfoxide. (A) H1650 cell apoptosis was measured by a flow cytometry after $48 \mathrm{~h}$; total apoptosis rates were then quantified. (B) Images of H1650 cell morphology. (C) H1975 cell apoptosis was measured by a flow cytometry after $48 \mathrm{~h}$; total apoptosis rates were then quantified. (D) Images of H1975 cell morphology. (E) A549 cell apoptosis was measured by a flow cytometry after $48 \mathrm{~h}$; total apoptosis rates were then quantified. (F) Images of A549 cell morphology. In the flow cytometry images, the lower left square represents living cells, the lower right square represents early apoptotic cells, the upper right square represents late apoptotic cells and the upper left square represents necrotic cells. Magnification, $x 200$. The mean \pm standard deviation was calculated from three independent experiments. $\left({ }^{*} \mathrm{P}<0.05,{ }^{* *} \mathrm{P}<0.01,{ }^{* * *} \mathrm{P}<0.001\right)$. EGFR, epidermal growth factor receptor.

The H1975 cell line possesses a T790M mutation that changes the binding site on EGFR and weakens the competition of
EGFR-TKIs (23). The H1650 cell line does not have PTEN expression, which negatively regulates the PI3K-AKT-mTOR 
A

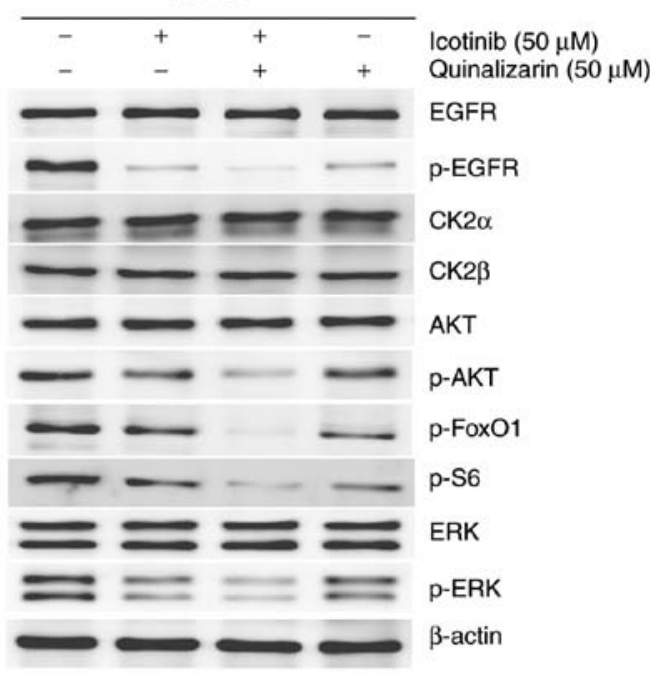

B

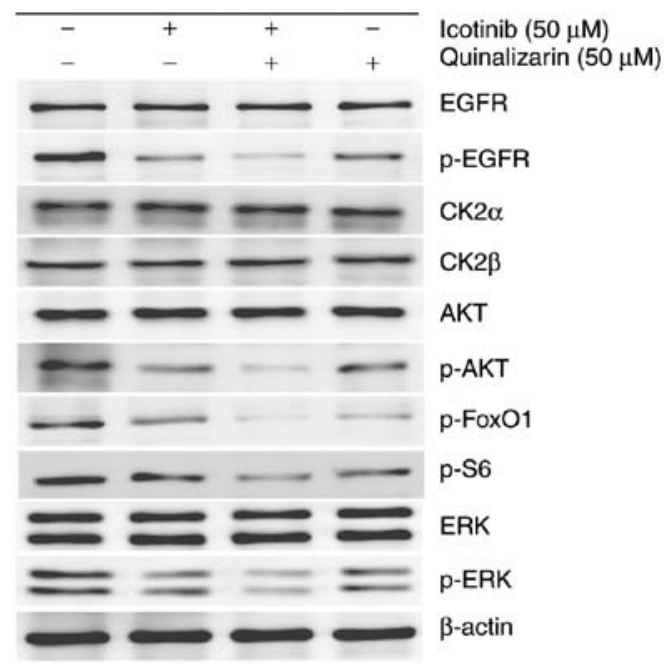

Icotinib+Quinalizarin Quinalizarin

H1650

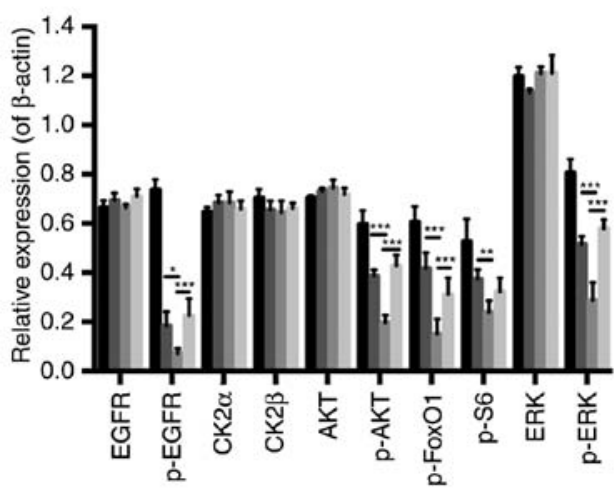

H1975

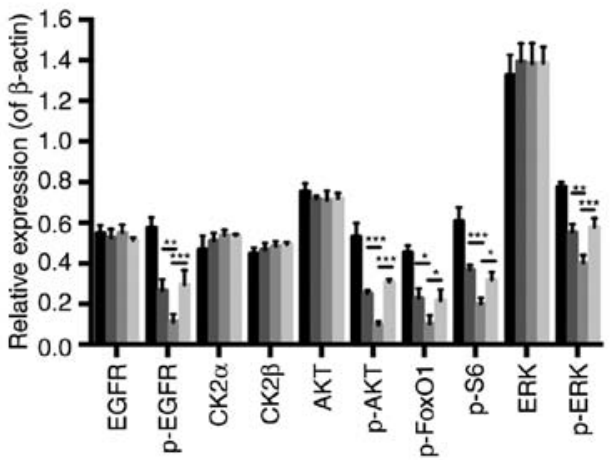

Figure 7. Quinalizarin and icotinib together decrease AKT and ERK protein expression in EGFR-resistant cell lines. EGFR-resistant cells were treated with $50 \mu \mathrm{M}$ icotinib and/or $50 \mu \mathrm{M}$ quinalizairn. The control group was treated with the equal concentration of dimethyl sulfoxide. Western blotting images and quantification of protein expression from (A) H1650 and (B) H1975 cells. $\beta$-actin was used as a loading control. The mean \pm standard deviation was calculated for three independent experiments. ( $\left.{ }^{*} \mathrm{P}<0.05,{ }^{* *} \mathrm{P}<0.01,{ }^{* * *} \mathrm{P}<0.001\right)$. EGFR, epidermal growth factor receptor; CK2 $\alpha / \beta$, casein kinase II subunit $\alpha / \beta ; \mathrm{p}-$, phosphorylated; FoxO1, forkhead box protein O1; S6, ribosomal protein S6 kinase $\beta-1$.

signaling pathway (38). In the current study, it was not surprising to find that H1975 and H1650 cells were resistant to icotinib, an EGFR-TKI

In the current study, quinalizarin inhibited cell viabilty in the cell lines that possessed wild-type EGFR and were EGFR-resistant, as well as in the EGFR-sensitive cells. Quinalizarin also promoted apoptosis in the cell lines that possessed wild-type $E G F R$ and were EGFR-resistant.CK2 plays an important role in the activation of the Ras-Raf-MEK-ERK signaling pathway $(39,40)$. CK2 inhibitors suppress the PI3K-AKT-mTOR signaling pathway and promote apoptosis $(24,41)$. The Ras-Raf-MEK-ERK and PI3K-AKT-mTOR signaling pathways are important for proliferation and apoptosis (42-44), which is why quinalizarin inhibited cell proliferation and promote apoptosis in these cells.

Additionally, in the current study, quinalizarin synergized with anti-tumor effects mediated by icotinib. The combination of quinalizarin with icotinib had a greater inhibitory effect on cell viability and further promoted apoptosis in the lung adenocarcinoma cells that were EGFR-resistant. The results of the current study were in line with the previous literature, which indicated that CK2 inhibition suppresses the PI3K-AKT-mTOR signaling pathway and promotes apoptosis by itself (41). Bliesath et al (45) insisted that the combination of EGFR-TKIs and CX-4945 shows better antitumor effects by suppressing the PI3K-AKT-mTOR signaling pathway compared with EGFR-TKI alone. In line with the study, the current results showed again that combining a CK2 inhibitor and icotinib together had better antitumor activity than icotinib alone, which might be explained by the fact that the combination treatment inhibited the activity of the PI3K-AKT-mTOR signaling pathway to a greater degree. So et al (46) reported that the CK2 inhibitor CX-4945 synergized with EGFR-TKIs on EGFR-mutant lung cancer cells (exon 19del and T790M), which were established as secondary resistant cell lines to EGFR-TKIs. In accordance with the aforementioned study, the current study demonstrated the potential ways in which quinalizarin was able to make the H1975 cells sensitive to icotinib. PTEN loss (H1650) has been shown to contribute to EGFR-TKI resistance (38) and CK2 further induces 
the stability of PTEN (18), which may be another way that quinalizarin acts to sensitize H1650 cells to icotinib.

Further experiments on the exact mechanism of the combination treatment were also conducted. The result showed that p-AKT and p-ERK were obviously downregulated when the cells were treated with both quinalizarin and icotinib. The Ras-Raf-MEK-ERK and PI3K-AKT-mTOR signaling pathways are main pathways that regulate cell survival and proliferation, and AKT and ERK are the key members of these two pathways. A number of studies insist that EGFR-TKIs play a pivotal role in anti-cancer therapy mainly by acting on these two signaling pathways $(47,48)$. Similarly, in the current study, CK2 inhibition by quinalizarin also had an impact on these two signaling pathways. Thus, it is reasonable to conclude that quinalizarin may sensitize cells to icotinib by inhibiting the proliferation and promoting the apoptosis mediated by AKT and ERK in EGFR-TKI-resistant human adenocarcinoma cell lines.

\section{Acknowledgements}

The authors sincerely thank Professor Mathias Montenarh from Medical Biochemistry and Molecular Biology, Saarland University (Homburg, Germany) for his time, support and valuable suggestions throughout the development of this paper.

\section{Funding}

This study was supported by The National Natural Science Foundation of China (grant no. 81101690 to RM and grant no. 81672979 to GW), The Foundation for Fostering Key Talents from Middle-aged and Young Medical Personnel in Wuhan (2016), Natural Science Foundation of Hubei Province of China (grant no. 2016cfb426).

\section{Availability of data and materials}

The datasets used and/or analyzed during the current study are available from the corresponding author on reasonable request.

\section{Authors' contributions}

GW and RM conceived and designed the experiment. KL and FZ performed the experiments. KL and YZ analyzed the data. QL and ZL interpreted the results and wrote the draft of the manuscript. SZ performed the MTT assay and LL performed part of the western blot analysis. SZ and LL wrote the final vision of the manuscript.

\section{Ethics approval and consent to participate}

Not applicable.

\section{Patient consent for publication}

Not applicable.

\section{Competing interests}

The authors declare that they have no competing interests.

\section{References}

1. Bareschino MA, Schettino C, Rossi A, Maione P, Sacco PC, Zeppa R and Gridelli C: Treatment of advanced non small cell lung cancer. J Thorac Dis 3: 122-133, 2011.

2. Shi Y, Au JS, Thong prasert S, Srinivasan S, Tsai CM, Khoa MT, Heeroma K, Itoh Y, Cornelio G and Yang PC: A prospective, molecular epidemiology study of EGFR mutations in asian patients with advanced non-small-cell lung cancer of adenocarcinoma histology (PIONEER). J Thorac Oncol 9: 154-162, 2014.

3. Wu YL, Chu DT, Han B, Liu X, Zhang L, Zhou C, Liao M, Mok T, Jiang H, Duffield E and Fukuoka M: Phase III, randomized, open-label, first-line study in asia of gefitinib versus carboplatin/paclitaxel in clinically selected patients with advanced non-small-cell lung cancer: Evaluation of patients recruited from mainland China. Asia-Pac J Clin Oncol 8: 232-243, 2012.

4. Mok TS, Wu YL, Thongprasert S, Yang CH, Chu DT, Saijo N, Sunpaweravong P, Han B, Margono B, Ichinose Y, et al: Gefitinib or carboplatin-paclitaxel in pulmonary adenocarcinoma. N Engl J Med 361: 947-957, 2009.

5. Thongprasert S, Duffield E, Saijo N, Wu YL, Yang JC, Chu DT, Liao M, Chen YM, Kuo HP, Negoro S, et al: Health-related quality-of-life in a randomized phase III first-line study of gefitinib versus carboplatin/paclitaxel in clinically selected patients from Asia with advanced NSCLC (IPASS). J Thorac Oncol 6: 1872-1880, 2011.

6. Ellis PM, Coakley N, Feld R, Kuruvilla S and Ung YC: Use of the epidermal growth factor receptor inhibitors gefitinib, erlotinib, afatinib, dacomitinib, and icotinib in the treatment of non-small-cell lung cancer: A systematic review. Curr Oncol 22: e183-e215, 2015

7. Jackman D, Pao W, Riely GJ, Engelman JA, Kris MG, Janne PA, Lynch T, Johnson BE and Miller VA: Clinical definition of acquired resistance to epidermal growth factor receptor tyrosine kinase inhibitors in non-small-cell lung cancer. J Clin Oncol 28: 357-360, 2010.

8. Gao Z, Chen W, Zhang X, Cai P, Fang X, Xu Q, Sun Y and $\mathrm{Gu}$ Y: Icotinib, a potent and specific EGFR tyrosine kinase inhibitor, inhibits growth of squamous cell carcinoma cell line A431 through negatively regulating AKT signaling. Biomed Pharmacother 67: 351-356, 2013.

9. Chen X, Zhu Q, Liu Y, Liu P, Yin Y, Guo R, Lu K, Gu Y, Liu L, Wang $\mathrm{J}$, et al: Icotinib is an active treatment of non-small-cell lung cancer: A retrospective study. PLoS One 9: e95897, 2014.

10. Liang W, Wu X, Fang W, Zhao Y, Yang Y, Hu Z, Xue C, Zhang J, Zhang J, Ma Y, et al: Network meta-analysis of erlotinib, gefitinib, afatinib and icotinib in patients with advanced non-small-cell lung cancer harboring EGFR mutations. PLoS One 9: e85245 2014.

11. Shi Y, Zhang L, Liu X, Zhou C, Zhang L, Zhang S, Wang D, Li Q, Qin S, Hu C, et al: Icotinib versus gefitinib in previously treated advanced non-small-cell lung cancer (ICOGEN): A randomised, double-blind phase 3 non-inferiority trial. Lancet Oncol 14: 953-961, 2013.

12. Antonicelli A, Cafarotti S, Indini A, Galli A, Russo A, Cesario A, Lococo FM, Russo P, Mainini AF, Bonifati LG, et al: EGFR-targeted therapy for non-small cell lung cancer: Focus on EGFR oncogenic mutation. Int J Med Sci 10: 320-330, 2013.

13. Zhou $C$ and Yao LD: Strategies to improve outcomes of patients with EGRF-mutant non-small cell lung cancer: Review of the literature. J Thorac Oncol 11: 174-186, 2016.

14. Yun CH, Mengwasser KE, Toms AV, Woo MS, Greulich H, Wong KK, Meyerson M and Eck MJ: The T790M mutation in EGFR kinase causes drug resistance by increasing the affinity for ATP. Proc Natl Acad Sci USA 105: 2070-2075, 2008.

15. Sequist LV, Waltman BA, Dias-Santagata D, Digumarthy S, Turke AB, Fidias P, Bergethon K, Shaw AT, Gettinger S, Cosper AK, et al: Genotypic and histological evolution of lung cancers acquiring resistance to EGFR inhibitors. Sci Transl Med 3: 75ra26, 2011.

16. Meggio F and Pinna LA: One-thousand-and-one substrates of protein kinase CK2? FASEB J 17: 349-368, 2003.

17. Ortega CE, Seidner Y and Dominguez I: Mining CK2 in cancer. PLoS One 9: e115609, 2014.

18. Torres J and Pulido R: The tumor suppressor PTEN is phosphorylated by the protein kinase CK2 at its $C$ terminus. implications for PTEN stability to proteasome-mediated degradation. J Biol Chem 276: 993-998, 2001. 
19. Cozza G, Mazzorana M, Papinutto E, Bain J, Elliott M di Maira G, Gianoncelli A, Pagano MA, Sarno S, Ruzzene M, et al: Quinalizarin as a potent, selective and cell-permeable inhibitor of protein kinase CK2. Biochem J 421: 387-395, 2009.

20. Daya-Makin M, Sanghera JS, Mogentale TL, Lipp M, Parchomchuk J, Hogg JC and Pelech SL: Activation of a tumor-associated protein kinase (p40TAK) and casein kinase 2 in human squamous cell carcinomas and adenocarcinomas of the lung. Cancer Res 54: 2262-2268, 1994.

21. Faust M, Schuster N and Montenarh M: Specific binding of protein kinase CK 2 catalytic subunits to tubulin. FEBS Lett 462 : 51-56, 1999.

22. Lee CK, Kim S, Lee JS, Lee JE, Kim SM, Yang IS, Kim HR, Lee JH, Kim S and Cho B: Next-generation sequencing reveals novel resistance mechanisms and molecular heterogeneity in EGFR-mutant non-small cell lung cancer with acquired resistance to EGFR-TKIs. Lung Cancer 113: 106-114, 2017.

23. Cross DA, Ashton SE, Ghiorghiu S, Eberlein C, Nebhan CA, Spitzler PJ, Orme JP, Finlay MR, Ward RA, Mellor MJ, et al: AZD9291, an irreversible EGFR TKI, overcomes T790Mmediated resistance to EGFR inhibitors in lung cancer. Cancer Discov 4: 1046-1061, 2014.

24. Di Maira G, Salvi M, Arrigoni G, Marin O, Sarno S, Brustolon F, Pinna LA and Ruzzene M: Protein kinase CK2 phosphorylates and upregulates Akt/PKB. Cell Death Differ 12: 668-677, 2005.

25. Duncan JS and Litchfield DW: Too much of a good thing: The role of protein kinase CK2 in tumorigenesis and prospects for therapeutic inhibition of CK2. Biochim Biophys Acta 1784: 33-47, 2008

26. Hay N: Interplay between FOXO, TOR, and Akt. Biochim Biophys Acta 1813: 1965-1970, 2011.

27. Wu SG and Shih JY: Management of acquired resistance to EGFR TKI-targeted therapy in advanced non-small cell lung cancer. Mol Cancer 17: 38, 2018

28. Chua MM, Ortega CE, Sheikh A, Lee M, Abdul-Rassoul H, Hartshorn KL and Dominguez I: CK2 in cancer: Cellular and biochemical mechanisms and potential therapeutic target. Pharmaceuticals (Basel) 10: E18, 2017.

29. Yaylim I and Isbir T: Enhanced casein kinase II (CK II) activity in human lung tumours. Anticancer Res 22: 215-218, 2002.

30. Hung MS, Xu Z, Chen Y, Smith E, Mao JH, Hsieh D, Lin YC, Yang CT, Jablons DM and You L: Hematein, a casein kinase II inhibitor, inhibits lung cancer tumor growth in a murine xenograft model. Int j Oncol 43: 1517-1522, 2013.

31. Li Q, Li K, Yang T, Zhang S, Zhou Y, Li Z, Xiong J, Zhou F, Zhou X, Liu L, et al: Association of protein kinase CK2 inhibition with cellular radiosensitivity of non-small cell lung cancer Sci Rep 7: 16134, 2017.

32. Kim J and Kim SH: Druggability of the CK2 inhibitor CX-4945 as an anticancer drug and beyond. Arch Pharm Res 35: 1293-1296, 2012.

33. Ku MJ, Park JW, Ryu BJ, Son YJ, Kim SH and Lee SY: CK2 inhibitor CX4945 induces sequential inactivation of proteins in the signaling pathways related with cell migration and suppresses metastasis of A549 human lung cancer cells. Bioorg Med Chem Lett 23: 5609-5613, 2013.

34. Di Maira G, Brustolon F, Bertacchini J, Tosoni K, Marmiroli S, Pinna LA and Ruzzene M: Pharmacological inhibition of protein kinase CK2 reverts the multidrug resistance phenotype of a CEM cell line characterized by high CK2 level. Oncogene 26 : 6915-6926, 2007.
35. Asati V, Mahapatra DK and Bharti SK: PI3K/Akt/mTOR and Ras/Raf/MEK/ERK signaling pathways inhibitors as anticancer agents: Structural and pharmacological perspectives. Eur J Med Chem 109: 314-341, 2016

36. Lieber M, Smith B, Szakal A, Nelson-Rees W and Todaro G: A continuous tumor-cell line from a human lung carcinoma with properties of type II alveolar epithelial cells. Int J Cancer 17: 62-70, 1976.

37. Greve G, Schiffmann I, Pfeifer D, Pantic M, Schuler J and Lubbert M: The pan-HDAC inhibitor panobinostat acts as a sensitizer for erlotinib activity in EGFR-mutated and -wildtype non-small cell lung cancer cells. BMC Cancer 15: 947, 2015.

38. Sos ML, Koker M, Weir BA, Heynck S, Rabinovsky R, Zander T, Seeger JM, Weiss J, Fischer F, Frommolt P, et al: PTEN loss contributes to erlotinib resistance in EGFR-mutant lung cancer by activation of Akt and EGFR. Cancer Res 69: 3256-3261, 2009.

39. Ritt DA, Zhou M, Conrads TP, Veenstra TD, Copeland TD and Morrison DK: CK2 is a component of the KSR1 scaffold complex that contributes to raf kinase activation. Curr Biol 17: 179-184, 2007.

40. Parker R, Clifton-Bligh R and Molloy MP: Phosphoproteomics of MAPK inhibition in BRAF-mutated cells and a role for the lethal synergism of dual BRAF and CK2 inhibition. Mol Cancer Ther 13: 1894-1906, 2014

41. So KS, Rho JK, Choi YJ, Kim SY, Choi CM, Chun YJ and Lee JC: AKT/mTOR down-regulation by CX-4945, a CK2 inhibitor, promotes apoptosis in chemorefractory non-small cell lung cancer cells. Anticancer Res 35: 1537-1542, 2015.

42. Yip PY: Phosphatidylinositol 3-kinase-AKT-mammalian target of rapamycin (PI3K-Akt-mTOR) signaling pathway in non-small cell lung cancer. Transl Lung Cancer Res 4: 165-176, 2015.

43. Reungwetwattana T and Dy GK: Targeted therapies in development for non-small cell lung cancer. J Carcinog 12: 22, 2013.

44. Zer A and Leighl N: Promising targets and current clinical trials in metastatic non-squamous NSCLC. Front Oncol 4: 329, 2014.

45. Bliesath J, Huser N, Omori M, Bunag D, Proffitt C, Streiner N, Ho C, Siddiqui-Jain A, O'Brien SE, Lim JK, et al: Combined inhibition of EGFR and CK2 augments the attenuation of PI3K-Akt-mTOR signaling and the killing of cancer cells. Cancer Lett 322: 113-118, 2012

46. So KS, Kim CH, Rho JK, Kim SY, Choi YJ, Song JS, Kim WS, Choi CM, Chun YJ and Lee JC: Autophagosome-mediated EGFR down-regulation induced by the CK2 inhibitor enhances the efficacy of EGFR-TKI on EGFR-mutant lung cancer cells with resistance by T790M. PLoS One 9: e114000, 2014.

47. Ke EE and $\mathrm{Wu}$ YL: EGFR as a pharmacological target in EGFR-mutant non-small-cell lung cancer: Where do we stand now? Trends Pharmacol Sci 37: 887-903, 2016.

48. Morgillo F, Della Corte CM, Fasano M and Ciardiello F Mechanisms of resistance to EGFR-targeted drugs: Lung cancer. ESMO Open 1: e000060, 2016.

This work is licensed under a Creative Commons Attribution-NonCommercial-NoDerivatives 4.0 International (CC BY-NC-ND 4.0) License. 